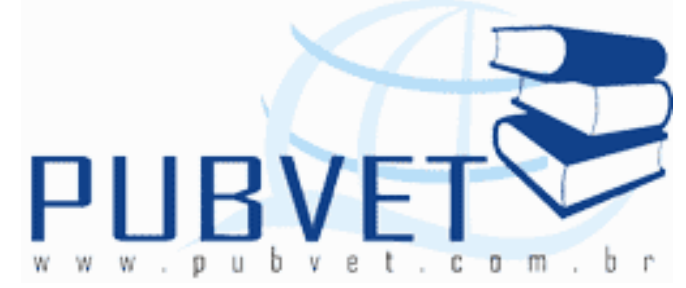

PUBVET, Publicações em Medicina Veterinária e Zootecnia.

\title{
Avaliações in vitro da fertilidade do sêmen equino
}

\section{Rodrigo Arruda de Oliveira}

Universidade de Brasília, Faculdade de Agronomia e Medicina Veterinária, Departamento de Reprodução Animal, Campus Universitário Darcy Ribeiro, Instituto Central de Ciências, Ala Sul, Asa Norte, CEP 70910-900, Brasília/DF, Brasil. E-mail: rodrigoarruda@unb.br

\section{Resumo}

Para que a inseminação artificial, principalmente com sêmen congelado, possa apresentar melhores resultados na espécie equina, é necessário o estudo mais amplo sobre vários aspectos. Deve-se aprofundar o conhecimento no que diz respeito à fisiologia da célula espermática, e aos testes aplicados para analisar a viabilidade dos espermatozoides submetidos à refrigeração, ao congelamento e ao descongelamento, uma vez que os danos ocasionados pela criopreservação causam prejuízos das funções celulares e, consequentemente, à redução da fertilidade. Dentre essas funções, a integridade da membrana espermática parece ser mais afetada e pode exercer papel crítico na sobrevivência do espermatozoide no trato genital da fêmea. Essa revisão tem como objetivo reunir informações sobre as principais e mais modernas técnicas de avaliação do sêmen equino in vitro, e apresentá-las de forma sintética.

Palavras-chave: Espermatozoide, garanhão, infertilidade, sondas fluorescentes 


\section{In vitro assessment of frozen semen's fertility}

\section{Abstract}

For better results with artificial insemination in the equine species, mainly with frozen semen, is necessary a broader study of several aspects. It should further knowledge concerning the sperm cell physiology, and the test that analyze the spermatozoa viability after cooling, freezing and thawing, since the damage caused by cryopreservation lead to losses in the cell function and, consequently, reduced fertility. Among these functions, the sperm cell membrane integrity seems to be the most affected and can play a critical role in the spermatozoa survival at the female genital tract. The objective of this review is to gather information about the main and most modern techniques of in vitro equine semen evaluation, and to synthetically present them.

Keywords: fluorescent probes; infertility; stallion; spermatozoa

\section{INTRODUÇÃO}

A utilização de biotécnicas cada vez mais modernas tem contribuído para o avanço da reprodução de diversas espécies animais, em especial os equinos, que exibem variação quanto às características de fertilidade seminal, entre animais, entre raças e entre diferentes ejaculados do mesmo garanhão.

Atualmente, a ciência possui técnicas laboratoriais precisas e modernas que auxiliam na avaliação das características do movimento espermático computadorizado, que apresenta dados de cinética espermática não mensurável ao olho humano. Entretanto, embora estas informações sejam valiosas, não são sempre uma informação real do potencial de fertilidade do sêmen.

A integridade das membranas espermáticas é crucial para a fertilização. Por este motivo, grande ênfase vem sendo dada ao uso das sondas fluorescentes, técnica de grande valor laboratorial por marcar estruturas 
específicas das células e detectar integridade estrutural ou funcionalidade de forma clara, sendo possível avaliar a integridade das membranas plasmática e acrossomal, juntamente com a avaliação do potencial de membrana mitocondrial.

Desde o início do século passado, pesquisadores têm procurado desenvolver testes laboratoriais eficazes que indiquem o potencial fertilizante do sêmen. No entanto, tais metas têm sido de difícil obtenção, uma vez que a maior parte dos problemas estão nos diferentes atributos que 0 espermatozoide deve possuir para fertilizar o óvulo.

Alguns problemas também existem para se mensurar a fertilidade. Fertilidade pode ser descrita como o percentual de embriões recuperados após a inseminação; do número de fêmeas que emprenharam após uma ou várias inseminações, em um ou vários ciclos, ou percentual de fêmeas que emprenharam no fim da estação de monta. A fertilidade também é dependente do número de espermatozoides na dose inseminante, idade das fêmeas e relação ovulação/inseminação, essas variáveis não são detectadas nas análises seminais (AMANN, 2005).

Apesar das dificuldades em correlacionar dados obtidos in vitro com in vivo, as avaliações laboratoriais quanto à qualidade do sêmen são importantes. Embora os testes laboratoriais não sejam fatores definitivos para predizer o potencial fertilizante do sêmen, essas análises podem indicar amostras de baixa fertilidade e permitem excluí-las de programas de inseminação artificial.

Essa revisão tem como objetivo reunir informações, e apresentá-las de forma sintética, sobre as principais e mais modernas técnicas de avaliação do sêmen equino in vitro.

\section{Análises laboratoriais de sêmen}

Motilidade, concentração e morfologia espermática são parâmetros clássicos na avaliação de amostras de sêmen (fresco, refrigerado e congelado). Usualmente, a motilidade espermática é avaliada pela observação de uma gota 
OLIVEIRA, R.A. Avaliações in vitro da fertilidade do sêmen eqüino. PUBVET, Londrina, V. 7, N. 26, Ed. 249, Art. 1646, Suplemento 2, 2013.

de sêmen entre lâmina e lamínula, enquanto as anormalidades espermáticas são avaliadas em esfregaços corados. Ambas as técnicas são realizadas sob uso de microscopia óptica. Entretanto, este tipo de análise manual pode ser imprecisa e subjetiva (experiência do técnico), e são influenciadas pela alta variação entre observações e observadores (ARRUDA et al., 2007).

Com o propósito de obter a técnica que demonstre maior precisão tanto para motilidade quanto para morfologia, diversos sistemas que utilizam a análise computadorizada de imagens têm sido desenvolvidos e empregados. Teoricamente, programas computadorizados para avaliação espermática podem ser mais objetivos e imprimir maior repetibilidade às avaliações do que a habilidade humana em identificar padrões de motilidade ou de normalidade espermáticas. O poder de análise deste tipo de teste é dado pela avaliação precisa e acurada dos espermatozoides com alto grau de objetividade, podendo assim aperfeiçoar o processo de avaliação seminal em animais (ARRUDA et al., 2007).

Para que a inseminação artificial, principalmente com sêmen congelado, possa apresentar melhores resultados na espécie equina, é necessário o estudo mais amplo sobre vários aspectos relacionados à fisiologia da célula espermática e à melhoria dos testes aplicados para analisar a viabilidade dos espermatozoides submetidos à refrigeração, ao congelamento e ao descongelamento, uma vez que os danos ocasionados pela criopreservação causam prejuízos das funções celulares, resultando em redução da fertilidade. Dentre essas funções, a integridade da membrana espermática parece ser mais afetada e pode exercer papel crítico na sobrevivência do espermatozoide no trato genital da fêmea (VARNER, 2008).

Nas espécies que possuem espermatozoides com acrossomo muito pequeno (rato, homem e cavalo), a visualização dos danos acrossomais usando microscopia óptica é dificultosa. Assim, técnicas de marcações específicas têm sido usadas para visualizar o acrossomo. Os métodos de coloração empregando corantes fluorescentes aumentaram a possibilidade de análise mais criteriosa da integridade estrutural dos espermatozoides. As 
OLIVEIRA, R.A. Avaliações in vitro da fertilidade do sêmen eqüino. PUBVET, Londrina, V. 7, N. 26, Ed. 249, Art. 1646, Suplemento 2, 2013.

sondas fluorescentes vêm sendo utilizadas isoladamente ou em combinação para determinar a integridade e a viabilidade celular. Alguns corantes fluorescentes específicos para DNA, por serem impermeáveis as membranas intactas, coram apenas células com membrana plasmática lesada. As lecitinas fluorescinadas se ligam de forma específica a glicoconjugados presentes no acrossomo, e também têm sido utilizadas para avaliar integridade do acrossomo em diversas espécies (VARNER, 2008).

Embora o uso de sondas fluorescentes pela microscopia venha sendo o método para avaliação da célula espermática, o número de espermatozoides normalmente examinados por análise não excede 200. A citometria de fluxo surge como técnica vantajosa sobre as outras clássicas para avaliação da viabilidade e integridade espermática, uma vez que este sistema automatizado tem a capacidade de examinar 10.000 espermatozoides em menos de um minuto, permitindo maior exatidão nos resultados e diminuição no tempo de preparação requerido em outras técnicas fluorescentes (ARRUDA et al., 2007).

Motilidade e velocidade (vigor) espermática

A análise da motilidade espermática é um indicador útil na avaliação da viabilidade espermática, pois é necessário que os espermatozoides tenham movimento para penetração na junção útero-tubárica, liberação dos sítios de armazenamento espermático no oviduto e penetração através das células que circundam o ovócito. Esses eventos podem estar comprometidos se as mitocôndrias estiverem afuncionais, se a membrana plasmática estiver lesada, se o espermatozóide tiver sofrido choque de temperatura ou se estiver morfologicamente anormal (GRAVANCE et al., 2000).

A motilidade espermática é excepcionalmente susceptível a condições ambientais (excesso calor ou frio, lubrificantes, luz, desinfetantes, e osmolaridade/pH do diluente do sêmen), sendo necessário proteger o sêmen desses agentes antes das análises (VARNER, 2008). 
OLIVEIRA, R.A. Avaliações in vitro da fertilidade do sêmen eqüino. PUBVET, Londrina, V. 7, N. 26, Ed. 249, Art. 1646, Suplemento 2, 2013.

Para aumentar a credibilidade dessa análise o procedimento deve ser conduzido por técnico experiente usando um microscópio óptico, preferencialmente binocular, com objetiva de 10 a 40x, equipado com mesa térmica. A avaliação é realizada com uma gota de sêmen entre lâmina e lamínula previamente aquecidas e mantidas a $37^{\circ} \mathrm{C}$, estimando o percentual de espermatozóides com movimento total e movimento progressivo (escala de 0 a $100 \%$ ) e a velocidade desse movimento ao cruzar o campo de observação (vigor) em uma escala de zero a cinco, onde zero é ausência de movimento progressivo com deslocamento de cauda lateral fraco e inexpressivo e cinco resulta em movimento vigoroso e veloz dos espermatozoides, geralmente progressivo (CBRA, 1998).

Mesmo com técnico experiente essa avaliação é subjetiva e sujeita a erros. A técnica moderna e mais objetiva é a análise computadorizada que já está presente em muitos laboratórios e centros de referência no Brasil e no mundo, tentando tornar essas avaliações mais objetivas.

Em garanhões, o método de avaliação computadorizada dos parâmetros da motilidade mostrou-se prático, rápido e de fácil execução, no entanto, ainda é necessário determinar qual ou quais dos parâmetros analisados podem contribuir para a inferência do potencial fecundante do sêmen (ARRUDA et al., 2007).

Para avaliação computadorizada do movimento espermático (CASA Computer-Assisted Semen Analyses) as análises do sêmen devem ser realizadas por um aparelho, que consiste em um computador, acoplado a um microscópio equipado com adaptador para vídeo-câmara. As imagens dos espermatozoides são capturadas e digitalizadas para serem analisadas pelo Software. Uma vez realizados os ajustes no aparelho, pelo menos cem células com movimento progressivo devem ser analisadas. Os parâmetros da motilidade espermática gerados pelo sistema são: motilidade progressiva, velocidade de trajeto, velocidade progressiva, velocidade curvilinear, amplitude lateral da cabeça, freqüência de batimentos, retilinearidade, linearidade e velocidade rápida (ARRUDA et al., 2007). 
A avaliação automatizada da motilidade dos espermatozoides é de grande interesse devido ao fato da cinética espermática ter relevância na determinação do potencial de fertilidade dos espermatozoides. Dentre esses parâmetros, a velocidade progressiva e os padrões de movimento celular têm sido correlacionados com penetração no muco cervical, penetração em óocitos de hamster e resultados de fertilização in vitro (VARNER, 2008).

Número de espermatozoides totais

O número de espermatozoides totais é indicador importante para avaliar a eficiência reprodutiva de um garanhão, pois é a partir desse dado que o técnico decide quantas fêmeas poderão ser cobertas ou inseminadas com um ejaculado desse genitor, assim como permite o uso de algumas biotécnicas, tais como diluição espermática, refrigeração e congelamento de sêmen.

Esse valor é resultado da multiplicação do volume livre de gel, concentração espermática e motilidade dos espermatozoides. O número de espermatozoides por ejaculado é sujeito à variação sazonal e também afetado por outros fatores, tais como: Frequência de ejaculação, idade, tamanho testicular, reserva extragonadal e patologias reprodutivas (CBRA, 1998).

A concentração espermática representa o número de espermatozoides por milímetro cúbico. O procedimento mais comum para se obter a concentração espermática consiste na contagem das células na câmara de Neubauer. Pode-se ainda utilizar espectrofotometria ou contadores automatizados (CBRA, 1998).

O sêmen é diluído em solução de formol-salina tamponada. A diluição deverá ser tal que, quando da contagem na câmara, o número de espermatozoides em cada retículo não seja excessivo, dificultando a contagem ou diluído em excesso, levando a identificação de raros espermatozoides por retículo. É necessária perfeita homogeneização da amostra diluída antes de coletar a alíquota para preenchimento da câmara. Com um tubo capilar, 
OLIVEIRA, R.A. Avaliações in vitro da fertilidade do sêmen eqüino. PUBVET, Londrina, V. 7, N. 26, Ed. 249, Art. 1646, Suplemento 2, 2013.

preenche-se dos dois lados. A câmara deve permanecer em repouso horizontal por 5 minutos, para que as células se depositem no fundo (CBRA, 1998).

Conta-se o número de espermatozoides de cinco quadrados de cada lado da câmara, obtêm-se a média e dividi-se pelo produto da altura da câmara, área de cada quadrado e diluição, como resultado tem-se o número de espermatozoides por milímetro cúbico (CBRA, 1998).

Morfologia espermática

A morfologia espermática vem sendo utilizada para avaliar a fertilidade do sêmen de garanhões e os defeitos morfológicos nos espermatozoides associados com a fertilidade reduzida (BALL \& MOHAMMED, 1995).

A estrutura ou morfologia do espermatozoide é frequentemente analisada em um microscópio de contraste de fase. São realizados esfregaços corados ou não, as colorações mais comuns são: Giemsa, hemotoxilina-eosina e eosina-negrosina, devido a fácil utilização (VARNER, 2008).

Cerca de duzentos espermatozoides são avaliados para evidenciar os defeitos morfológicos, relatando o tipo e a incidência de cada um. Os defeitos espermáticos podem ser divididos defeitos maiores e menores. São considerados defeitos maiores os de origem testicular durante a espermatogênese e os menores os originários nos ductos, após a célula deixar o testículo e os, criados in vitro, decorrentes de procedimentos impróprios de coleta e manipulação seminal, enfatizando o efeito global no potencial fertilizante, portanto os defeitos maiores estão associados com redução na fertilidade e os defeitos menores têm efeito reduzido na fertilização, e podem ser compensados aumentando o número de espermatozoides na dose inseminante (GRAHAM \& MOCÉ, 2005).

Alguns defeitos que podem ser encontrado nos esfregaços são: formas subdesenvolvidas, duplas, defeitos de acrossoma, diadema, cabeça piriforme, cabeça estreita na base, cabeça com contorno anormal, cabeça pequena anormal, cabeça solta anormal, gota proximal, pseudo-gota, cauda fortemente 
OLIVEIRA, R.A. Avaliações in vitro da fertilidade do sêmen eqüino. PUBVET, Londrina, V. 7, N. 26, Ed. 249, Art. 1646, Suplemento 2, 2013.

enrolada, cabeça estreita, cabeça pequena normal, cabeça gigante curta larga, cabeça solta normal, membrana acrossomal destacada, gosta distal, cauda simplesmente enrolada, cauda enrolada terminal, entre outros (CBRA, 1998).

As avaliações da morfometria espermática pelo sistema computadorizado, são realizadas, normalmente, por esfregaços corados, em aumento de 1.000 vezes. As imagens destinadas à avaliação da morfometria da cabeça dos espermatozoides são avaliadas por um Software instalado no aparelho de análise computadorizada (ARRUDA et al., 2007). Determinando parâmetros como largura, comprimento e área da cabeça do espermatozoide e correlacionar esses dados, que podem ser utilizados para categorizar garanhões em grupos férteis e subfertéis (CASEY et al., 1997).

No geral o percentual de espermatozoides morfologicamente normais é similar ao percentual de células com movimento progressivo. Se a motilidade espermática é baixa e o percentual de estruturas morfologicamente normais é alto, sugere-se que erros laboratoriais ocorreram (VARNER, 2008).

Integridade da membrana plasmática

A integridade da membrana plasmática é frequentemente sinônimo de viabilidade espermática, porque para fertilizar um óocito, o espermatozoide deve ter a membrana íntegra e funcional. É responsável pelo mecanismo de manutenção do equilíbrio osmótico celular, atuando como barreira entre os meios intra e extracelulares. Danos nesta estrutura podem levar a perda da homeostase com posterior morte da célula (AMAN \& PICKETT, 1987). Assim, a integridade da membrana plasmática exerce papel fundamental para sobrevivência do espermatozoide no trato genital da fêmea e para manutenção de sua capacidade fertilizante (PARKS \& GRAHAM, 1992).

A integridade da membrana plasmática pode ser avaliada visualmente por microscopia óptica ou de fluorescência, no entanto não é uma estrutura homogênea, mas é dividida em vários domínios e diferentes testes só avaliam um único domínio. Por exemplo, o teste hiposmótico permite a avaliação da 
OLIVEIRA, R.A. Avaliações in vitro da fertilidade do sêmen eqüino. PUBVET, Londrina, V. 7, N. 26, Ed. 249, Art. 1646, Suplemento 2, 2013.

membrana que recobre a peça principal. Para este teste, o sêmen é incubado em meio hiposmótico e avaliado por microscopia óptica. Se a membrana plasmática que cobre a peça principal está intacta a cauda do espermatozoide irá enrolar, enquanto a que não está intacta a cauda não se dobrara (NEILD et al., 2000).

A integridade da membrana que cobre a cabeça do espermatozoide é avaliada após coloração das células. O corante mais utilizado é a Eosinanegrosina para esfregaços secos, enquanto que a combinação de Diacetato de Carboxifluoresceína (CFDA) com Iodeto de Propídio (IP) é comumente utilizada para coloração de esfregaços úmidos, devendo ser avaliadas por microscopia de fluorescência. O IP possui afinidade ao DNA e cora em vermelho o núcleo de células com membrana plasmática lesada. O CFDA é um substrato incolor permeável a membrana que é hidrolisado rapidamente por esterases no interior da célula, produzindo o diacetato de carboxifluoresceína livre que é retido dentro da célula com membrana plasmática intacta, exibindo fluorescência de coloração verde amarelada (GARNER et al., 1997).

Por ser um corante fluorescente muito estável, o IP vem sendo utilizado em vários trabalhos, apresentando êxito nos resultados tanto em microscopia de fluorescência quanto em sistema de citometria de fluxo (GILLAN et al., 2005).

HARRISON \& VICKERS (1990) utilizaram a associação de sondas fluorescentes, CFDA e IP, para avaliação da integridade de membrana plasmática de espermatozoides e concluiram que essa técnica fornece dados mais confiáveis do percentual de células funcionais que avaliações de motilidade ou integridade acrossomal.

Integridade da membrana acrossomal

A reação acrossômica, caracterizada pela liberação das enzimas acrossomais, é evento essencial para penetração do espermatozoide na zona pelúcida e fusão com a membrana plasmática do oócito. Portanto, a 
OLIVEIRA, R.A. Avaliações in vitro da fertilidade do sêmen eqüino. PUBVET, Londrina, V. 7, N. 26, Ed. 249, Art. 1646, Suplemento 2, 2013.

integridade do acrossomo, bem como a manutenção de suas enzimas, é crucial para que ocorra a fertilização (GARNER \& HAFEZ, 1995).

A integridade do acrossomo pode ser verificada por diferentes técnicas de fluorescência. Técnicas de imunofluorescência também podem identificar acrossomos lesados por preenchimento secundário com fluoróforos (THOMAS et al., 1997). Ainda, o caráter glicoprotéico dos componentes acrossomais fornece outro meio de mensurar a integridade acrossomal, por preenchimento fluorescente da matriz acrossomal de espermatozóides com acrossomo lesado com lecitinas marcadas (GRAHAM et al., 1990).

As aglutininas, tais como aglutinina de Pisum sativum (PSA), de Ricinus communis (RCA), de Arachis hypogea (PNA) ou Concanavalia ensiformis (ConA), que possuem especificidade a glicoproteínas da membrana acrossomal, têm sido usadas para determinar a integridade acrossomal. Para visualização do acrossomo espermático em microscopia de fluorescência, estas aglutininas devem ser conjugadas a fluoresceínas, tais como o isotiocionato de fluoresceína (FITC) (CROSS \& MEIZEL, 1989)

A aglutinina de Pisum sativum (PSA), é uma aglutinina da ervilha, que se liga aos glicoconjugados da matriz acrossomal (a-manose e a-galactose). Quando conjugada ao FITC, marca com sucesso o acrossomo espermático em verde amarelado, facilita a visualização e identifica acrossomos lesados (CROSS \& MEIZEL, 1989).

FARLIN et al. (1992) avaliaram a eficácia do protocolo Pisum SativumFITC em identificar danos ao acrossomo de espermatozoides equinos, utilizando misturas em diversas proporções de células intactas e danificadas. A ligação de FITC-PSA aumentou nas amostras com células lesadas (congeladas/descongeladas) em relação ao sêmen fresco (acrossoma intacto), concluindo que o protocolo FITC-PSA pode ser utilizado para determinar integridade acrossomal no sêmen fresco e congelado de garanhões. 
OLIVEIRA, R.A. Avaliações in vitro da fertilidade do sêmen eqüino. PUBVET, Londrina, V. 7, N. 26, Ed. 249, Art. 1646, Suplemento 2, 2013.

Integridade e função da membrana mitocondrial

Nas células espermáticas as mitocôndrias estão dispostas de forma helicoidal na peça intermediária e o ATP produzido serve como suplemento energético para os batimentos flagelares. Portanto, é indispensável que haja produção de ATP pelas mitocôndrias para haver motilidade espermática (COSSON, 1996).

Muitos indicadores para monitoramento do potencial de membrana de mitocôndrias têm sido discutidos com grande ênfase em favor das sondas fluorescentes. Os componentes com sensitividade ao potencial de membrana mitocondrial mais comuns são as rodaminas e carbocianinas. O sucesso para o uso dessas sondas em células vivas é baseado no fato de não serem destrutivas nem causarem toxicidade (REERS et al., 1991).

Essas sondas fluorescentes são transportadas para o interior da célula pela respiração mitocondrial, portanto, quanto mais funcional mais corante será acumulado (GRAHAM \& MOCÉ, 2005).

A Rodamina 123 (R123) é um fluorocromo capaz de corar mitocôndrias e promover imagens de alta fluorescência em células vivas. No entanto, identifica somente população de células com função mitocondrial, não possuindo a capacidade de diferenciar mitocôndrias com potencial de membrana alto ou baixo (GRAHAM \& MOCÉ, 2005).

Um tipo especial de multímeros de carbocianinas (3,3'dipentilthiodicarbocianina), tem sido explorado para visualizar mitocôndrias em uma variedade de células, sendo o mais utilizado o corante identificado como sendo iodeto de 5, 5',6,6'-tetracloro-1,1,3,3'tetraetilbenzimidazolilcarbocianina (JC-1) (REERS et al., 1991).

O JC-1 identifica populações de mitocôndrias com diferentes potenciais de membrana através de códigos de cor. Sua cor é alterada do verde para o laranja ou vermelho, com aumento do potencial de membrana (REERS et al., 1991). Em baixas concentrações o JC-1 forma monômeros e exibe fluorescência verde, enquanto em altas concentrações forma J-agregados com 
OLIVEIRA, R.A. Avaliações in vitro da fertilidade do sêmen eqüino. PUBVET, Londrina, V. 7, N. 26, Ed. 249, Art. 1646, Suplemento 2, 2013.

fluorescência laranja. Portanto o JC-1 não identifica somente mitocôndria funcional de não funcional, mas permite analisar níveis de funcionalidade da membrana, pela intensidade das colorações (GRAHAM \& MOCÉ, 2005).

A sonda fluorescente $\mathrm{JC}-1$ vem sendo utilizada como suporte no diagnóstico de infertilidade humana, identificando espermatozóides com baixo potencial de membrana mitocondrial e pode detectar mudanças no potencial de membrana de espermatozóides eqüinos (GRAVANCE et al., 2000).

GRAVANCE et al. (2000) avaliaram a eficácia da sonda JC-1 para análise da função mitocondrial do espermatozoide equino e concluíram que as variações de coloração verde e laranja, determinado pela intensidade relativa da fluorescência, são indicadores satisfatórios, podendo detectar mudanças no potencial de membrana mitocondrial.

Avaliação da estrutura da cromatina espermática

A integridade da cromatina é essencial para o desenvolvimento embrionário após fertilização e união dos pró-núcleos feminino e masculino. Espermatozoides que possuem núcleos irregulares apresentam cromatina com estrutura alterada e essas alterações podem ser detectadas por padrões anormais de desnaturação do DNA em testes específicos (HAMAMAH et al., 1990).

O DNA de células de morfologia irregular é menos resistente à desnaturação térmica. Todavia, muitos espermatozoides normais de doadores subférteis também são anormalmente susceptíveis à desnaturação térmica de seu DNA, sendo que a sensibilidade da cromatina ao estresse térmico pode ser um determinante adicional da fertilidade (HAMAMAH et al., 1990).

A avaliação da estrutura da cromatina espermática tem sido realizada com o uso da acridina laranja, um corante fluorescente que se intercala a dupla fita de DNA e fluoresce em verde quando esta se apresenta íntegra. Quando associado com a porção desnaturada da fita de DNA, a acridina emite 
fluorescência laranja, permitindo a quantificação de desnaturação das células (HAMAMAH et al., 1990).

Tem-se demonstrado que a qualidade do DNA espermático de alguns garanhões de menor fertilidade pode declinar a uma taxa maior do que a observada em garanhões férteis com condições de estocagem similares (LOVE, 2005). A desnaturação da cromatina é mais alta no sêmen de garanhões subférteis em comparação a garanhões férteis (32\% versus $16 \%$ ) e o escore de desnaturação é negativamente correlacionado com a taxa de prenhez (KENNEY et al., 1995).

Associação de sondas fluorescentes

As associações de sondas fluorescentes permitem avaliar simultaneamente mais do que um compartimento da célula espermática. De acordo com TARTAGLIONE \& RITTA (2004), quanto mais parâmetros espermáticos são avaliados em uma amostra de sêmen, maior será o valor no prognóstico da fertilidade in vitro.

Diversas associações de sonda foram utilizadas por vários pesquisadores nos últimos anos (GRAHAM et al., 1990; GARNER et al., 1997; THOMAS et al., 1997).

As sondas fluorescentes também podem ser utilizadas na citometria de fluxo, que é um sistema que avalia células em suspensão isoladamente, podendo obter facilmente informações de subpopulações em uma amostra, o que o faz ideal para análises de populações heterogêneas, como os espermatozoides (GILLAN et al., 2005). Sua análise é objetiva, avaliando a quantidade de sondas fluorescentes que estão associadas às células de maneira precisa, podendo ser feita em dezenas de milhares de células em aproximadamente um minuto e ainda permite a associação de sondas fluorescentes no espermatozóide (GRAHAM et al., 1990).

Uma técnica de avaliação simultânea das membranas plasmática, acrossomal e mitocondrial, que forneça informações mais precisas e acurada 
sobre a qualidade seminal é de extrema importância. Contudo, em uma central de biotecnologia de sêmen, um grande número de amostras deve ser processado e avaliado. Desta forma, esta técnica deve apresentar menor dispêndio de tempo e de custo para que sua aplicação seja rotineira (ARRUDA et al., 2007).

Peroxidação lipídica da membrana espermática

O espermatozoide, como qualquer outra célula em condições aeróbicas, produz espécies reativas de oxigênio (EROS), sendo a maior parte delas originadas do metabolismo normal da célula. Dentre as EROS formadas, podemos citar o anion superóxido, o peróxido de hidrogênio, os radicais hidroxil, hidroperoxil, peroxil e alcoxil e ainda o ácido hipocloroso (AITKEN \& KRAUSZ, 2001).

No plasma seminal existem enzimas e algumas moléculas com ação antioxidante, tais como a glutationa peroxidase, superóxido desmutase, catalase, vitamina $E$, vitamina $C$, uratos, albumina, taurina, hipotaurina, entre outras (KANKOFER et al., 2005).

Esses agentes controlam a produção de pró-oxidantes, como as EROS, prevenindo possíveis danos celulares. Porém, na presença de um grande número de células inflamatórias e espermatozoides defeituosos, ou em procedimentos que diminuam acentuadamente a quantidade de plasma seminal, há um aumento na produção de EROS (BAUMBER et al., 2000).

A produção excessiva de EROS, além da capacidade antioxidante do sêmen, determina o estresse oxidativo que causa disfunções na própria célula espermática por diferentes mecanismos, como a peroxidação dos lipídeos da membrana plasmática, inibição do metabolismo, da motilidade e da capacidade fecundante (BAUMBER et al., 2000).

Apesar desses efeitos prejudiciais, a produção de espécies reativas de oxigênio faz parte do funcionamento normal da célula espermática, uma vez que baixas concentrações de EROS estão envolvidas com a hiperativação dos 
OLIVEIRA, R.A. Avaliações in vitro da fertilidade do sêmen eqüino. PUBVET, Londrina, V. 7, N. 26, Ed. 249, Art. 1646, Suplemento 2, 2013.

espermatozoides, sendo sua produção um pré-requisito para capacitação espermática, além de ser relacionada a ligação com a zona pelúcida e fusão do espermatozoide com o oócito (AITKEN \& KRAUSZ, 2001).

A detecção da peroxidação lipídica do espermatozoide pode ser feita pela detecção de produtos finais deste processo, como o malondialdeído, ou pela avaliação dos lipídios de membrana pela cromatografia. Estes métodos são sensíveis, porém são trabalhosos e medem a peroxidação da membrana de forma indireta. Uma alternativa para verificação da peroxidação lipídica é a utilização de sondas fluorescentes lipofílicas. A mais amplamente utilizada é um análogo de ácido graxo, o ácido cis-parinárico (cis-PnA). Outras sondas fluorescentes utilizadas são derivadas de fluoresceína e lipídios (BALL \& VO, 2002).

A sonda fluorescente BODIPY (4,4-difluoro-3a,4adiaza-s-s-indacene) tem intensidade de fluorescência intrinsecamente lipofílica, podendo mimetizar as propriedades de lipídeos naturais. A partir dele, foi desenvolvida uma família de sondas com análogos de ácidos graxos, fosfolípideos e ésteres de colesterol, dentre eles está o C11-BODIPY, que se incorpora à membrana celular. Enquanto está intacta, é observada uma fluorescência vermelha, já na presença de EROS, ocorre peroxidação lipídica, que acarreta mudança da fluorescência de vermelha para verde. Por estas características, esta sonda é considerada prática para detectar peroxidação lipídica e capacidade de oxidação de células vivas, inclusive espermatozoides, podendo ser utilizada na citometria de fluxo ou em outros aparelhos com leitores a laser (BALL \& VO, 2002).

Avaliação espermática por citometria de fluxo

A citometria de fluxo é um recurso emergente na medicina veterinária que permite a análise rápida, objetiva e quantitativa de células em suspensão. Apesar do alto custo e da necessidade de técnicos especializados para realização da avaliação citofluorométrica, esta técnica tem sido aplicada em 
OLIVEIRA, R.A. Avaliações in vitro da fertilidade do sêmen eqüino. PUBVET, Londrina, V. 7, N. 26, Ed. 249, Art. 1646, Suplemento 2, 2013.

diversos projetos científicos relacionados à medicina veterinária no Brasil (NAKAGE et al., 2005).

O citômetro de fluxo é utilizado para avaliação da emissão de fluorescência das células. Alguns aparelhos são capazes de separar fisicamente as células, de acordo com as características citométricas (NAKAGE et al., 2005).

As células da amostra em suspensão são marcadas com reagentes fluorescentes específicos para detecção de moléculas de superfície e são introduzidas em câmara de fluxo vibratória. O fluxo de células que atravessa a câmara é envolvido por solução tampão, sendo que 500 a 4000 células ou partículas passam em fila simples por segundo por meio do sensor eletrônico. O fluxo é iluminado por laser de argônio (azul). Cada célula é avaliada com relação ao tamanho e granulosidade e para intensidade de fluorescência para deteç̧ão de antígenos de superfície diferentes. A vibração do fluxo celular provoca o rompimento em gotículas que podem ser carregadas eletricamente e, a partir daí, dirigidas por placas de deflexão eletromagnética para serem coletadas em diferentes populações celulares de acordo com os parâmetros medidos, sob controle de um computador (NAKAGE et al., 2005).

A integridade da membrana plasmática é essencial para o funcionamento do espermatozóide. Diferentes métodos de avaliação da integridade das membranas plasmática e acrossomal têm sido testados, entre estes testes pode-se citar os que usam fluorocromos. Estas avaliações, quando analisadas por microscopia de fluorescência, apenas avaliam de 100 a 200 células. Entretanto há ganho considerável quando o uso de sondas fluorescentes para análise das organelas é combinado com o uso da citometria de fluxo, já que a citometria permite a análise de milhares de células por segundo (ARRUDA et al., 2007).

Em garanhões, essa técnica tem sido aplicada para avaliar integridade das membranas plasmática, acrossomal e mitocondrial, integridade do DNA, peroxidação lipídica, capacitação e reação acrossômica (ARRUDA et al., 2007). 


\section{CONSIDERAÇÕES FINAIS}

A espécie equina apresenta índices de fertilidade dos mais baixos entre os animais domésticos em decorrência da seleção zootécnica. Observa-se que os únicos parâmetros de seleção praticados referem-se ao andamento e à morfologia, esquecendo por completo o desempenho reprodutivo. Devido a este fato, a reprodução equina hoje em dia é a mais dispendiosa na produção animal, o que justifica melhorar o seu rendimento pelo aumento da fertilidade.

A fertilidade varia entre os garanhões, mesmo quando estes reúnem as qualidades mínimas. Vários métodos laboratoriais para avaliação do sêmen vêm sendo utilizados. Estes, em conjunto, podem ajudar a predizer seu potencial fecundante, tais como, análises computadorizadas do movimento e da morfologia espermática, composição do plasma seminal, integridade da membrana plasmática e acrossomal, função mitocondrial, desnaturação da cromatina, peroxidação das membranas espermáticas, entre outros. No entanto, nenhum teste laboratorial isolado pode estimar este potencial, apenas permite excluir partidas de sêmen que certamente apresentarão baixa fertilidade. Até que a ciência evolua a ponto de desenvolver uma ou mais técnicas que sejam marcadores confiáveis de fertilidade, a inseminação de éguas é a única forma de se conhecer o potencial de fertilidade do sêmen equino.

\section{REFERÊNCIAS}

1. AITKEN, R. J.; KRAUSZ, C. Oxidative stress, DNA damage and the $\mathrm{Y}$ chromosome. Reproduction, v. 122, p. 497-506, 2001.

2. AMANN, R. P.; PICKETT, B. W. Principles of cryopreservation and review of cryopreservation of stallion spermatozoa. Journal of Equine Veterinary Science, v. 7, p. 145-173, 1987.

3. AMANN, R. P. Weaknesses in reports of "fertility" for horses and other species. Theriogenology, v. 63, p. 698-715, 2005. 
4. ARRUDA, R. P.; ANDRADE, A. F. C.; PERES, K. R.; RAPHAEL, C. F.; NASCIMENTO, J.; CELEGHINI, E. C. C. Biotécnicas aplicadas à avaliação do potencial de fertilidade do sêmen eqüino. Revista Brasileira de Reprodução Animal, v. 31, p. 8-16, 2007.

5. BALL, B. A.; MOHAMMED, H. O. Morphometry of stallion spermatozoa by computed-assisted image analysis. Theriogenology, v. 44, p. 367-377, 1995.

6. BALL, B. A.; VO, A. Detection of lipid peroxidation in equine spermatozoa based upon the lipophilic fluorescent dye C1I-BODIPY581/591. Journal of Andrology, v. 23, p. 259-269, 2002.

7. BAUMBER, J.; BALL, B. A.; GRAVANCE, C. G; MEDINA, V.; DAVIES-MOREL, M. C. The effect of reactive oxygen species on equine sperm motility, viability, acrosomal integrity, mitochondrial membrane potential and membrane lipid peroxidation. Journal of Andrology, v. 21 , p. $895-902,2000$.

8. COLÉGIO BRASILEIRO DE REPRODUÇÃO ANIMAL. Manual para exame andrológico e avaliação de sêmen animal: manual de orientação. Belo Horizonte, 1998. 49 p.

9. CASEY, P. J.; GRAVANCE, C. J.; DAVIS, R. O.; CHABOT, D. D.; LIU, I. K. M. Morphometric differences in sperm head dimensions of fertile and subfertile stallions. Theriogenology, $v$. 47, p. $575-582,1997$.

10. COSSON, J. A moving image of flagella: news and views on the mechanisms involved in axonemal beating. Cell Biology International, v. 20, p. 83-94, 1996.

11. CROSS, N. L.; MEIZEL, S. Methods for evaluating the acrosomal status of mammalian sperm. Biology of Reproduction, v. 41, p. 635-641, 1989.

12. FARLIN, M.E.; JASKO, D.J.; GRAHAM, J.K.; SQUIRES, E.L. Assessment of Pisum sativum agglutinin in identifying acrosomal damage in stallion spermatozoa. Molecular Reproduction and Development, v.22, p.23-27, 1992.

13. GARNER, D. L.; HAFEZ, E. S. E. Espermatozóide e plasma seminal. In: HAFEZ, E. S. E. Reprodução Animal. 6.ed. São Paulo: Editora Manole, 1995. cap. 7, p. 167-190.

14. GARNeR, D. L.; THOMAS, A. C.; JOERG, H. W.; DEJARNeTtE, J. M.; MARShALL, C. E. Fluorometric assessment of mitochondrial function and viability in cryopreserved bovine spermatozoa. Biology of Reproduction, v. 57, p. 1401-1406, 1997.

15. GILLAN, L.; EVANS, G.; MAXWELL, W. M. C. Flow cytometric evaluation of sperm parameters in relation to fertility potential. Theriogenology, v. 63, p. 445-457. 2005.

16. GRAHAM, J. K.; KUNZE, E.; HAMMERSTEDT, R. H. Analysis of sperm cell viabilty, acrosomal integrity, and mitochondrial function using flow cytometry. Biology of Reproduction, v. 43, p. 55-64, 1990.

17. GRAHAM, J. K.; MOCÉ, E. Fertility of frozen/thawed semen. Theriogenology, v. 64, p. 492-504, 2005.

18. GRAVANCE, C. G.; GARNER, D. L.; BAUMBER, J.; BALL, B. A. Assessment of equine sperm mitochondrial function using JC-1. Theriogenology, v. 53, p. 1691-1703, 2000. 
19. HAMAMAH, S.; ROYÈRE, D.; NICOLLE, J. C.; PAQUIGNON, M.; LANSAC, J. Effects of freezing-thawing on the spermatozoon nucleus: a comparative chromatin cytophotometric study in the porcine and human species. Reproduction Nutrition Development, v. 30, p. 59-64, 1990.

20. HARRISON, R.A.P.; VICKERS, S.E. Use of fluorescent probes to assess membrane integrity in mammalian spermatozoa. Journal of Reproduction and Fertility, v.88, p.343-352, 1990.

21. KANKOFER, M.; KOLM, G.; AURICH, J.; AURICH, C. Activity of glutathione peroxidase, superoxide dismutase and catalase and lipid peroxidation intensity in stallion semen during storage of $5^{\circ} \mathrm{C}$. Theriogenology, v. 63, p. 1354-1365, 2005.

22. KENNEY, R.M.; EVENSON, D.P.; GARCIA, M.C.; LOVE, C.C. Relationship between sperm chromatin structure, motility and morphology of ejaculated sperm and seasonal pregnancy rate. Biology of Reproduction Mono, n.1, p.647-653, 1995.

23. LOVE, C.C. The sperm chromatin structure assay: A review of clinical applications. Animal Reproduction Science, v.89, p.39-45, 2005.

24. NAKAGE, A. P. M.; SANTANA, A. E.; CÁPUA, M. L. B.; COELHO, P.S. Metodologia e aplicação da citometria de fluxo na hematologia veterinária. Ciência Rural, v. 35, p. 966-973, 2005.

25. NEILD, D. M.; CHAVES, M. G.; FLORES, M.; MIRAGAYA, M. H.; GONZALES, E.; AGÜERO, A. The HOS test and its relationship to fertility in the stallion. Andrologia, v. 32, p. 351-355, 2000.

26. PARKS, J. E.; GRAHAM, J. K. Effects of cryopreservation procedures on sperm membranes. Theriogenology, v. 38, p. 209-222, 1992.

27. REERS, M.; SMITH, T. W.; CHEN, L. B. J-aggregate formation of a carbocyanine as a quantitative fluorescent indicator of membrane potential Biochemistry, v. 30, p. 4480-4486, 1991.

28. TARTAGLIONE, C. M.; RITTA, M. N. Prognostic value of spermatological parameters as predictors of in vitro fertility of frozen-thawed bull semen. Theriogenology, v. 62, p. 1245$1252,2004$.

29. THOMAS, C. A.; GARNER, D. L.; DEJARNETTE, J. M.; MARSHALL, C. E. Fluorometric assessments of acrosomal integrity and viability in cryopreserved bovine spermatozoa. Biology of Reproduction, v. 56, p. 991-998, 1997.

30. VARNER, D. D. Developments in stallion semen evaluation. Theriogenology, v. 70, p. 448-462, 2008. 